\title{
Construindo as competências do professor do ensino superior no Brasil: uma análise de trajetórias de docentes de escola de negócios
}

\author{
Building the teacher's competences higher education in Brazil: an \\ analysis of trajectories of business school teachers
}

\section{Construisant les compétences du professeur d' enseignement supérieur au Brésil: analyse de trajectoires des professeurs d'écoles de commerce}

\section{Cecília Berger ${ }^{4}$}

Pontifícia Universidade Católica do Paraná, Programa de Pós-graduação em Administração

(Mestrado e Doutorado)

http://lattes.cnpq.br/1756150811159554

https://orcid.org/0000-0001-7698-6329

Leandro Figueira Neto

Pontifícia Universidade Católica do Paraná, Programa de Pós-graduação em Administração

(Mestrado e Doutorado), Mestrando

http://lattes.cnpq.br/9012548097951471

https://orcid.org/0000-0002-1361-2570

Alboni Marisa Dudeque Pianouski Uieira ${ }^{3}$

Pontifícia Universidade Católica do Paraná, Programa de Pós-graduação em Educação (Mestrado e Doutorado), Professora; Revista Diálogo Educacional, Editora http://lattes.cnpq.br/0198429449537597

http://orcid.org/0000-0003-3759-0377

Resumo: Desde o final da década de 1990, a demanda por educação superior em administração aumentou no Brasil, proporcionando benefícios às universidades particulares. Embora esse ambiente ofereça grande oportunidade para as escolas de negócios, ele também implica uma série de questões desafiadoras, que impactam a cadeia de valor do ensino. Entendendo serem as pessoas o grande diferencial das organizações bem-sucedidas, este artigo teve por objetivo refletir sobre a necessidade de as universidades particulares buscarem no corpo docente suas bases para a vantagem competitiva. Baseando-se no conceito de competências profissionais, argumenta-se que as competências dos docentes são estritamente relacionadas ao seu contexto de atuação, devendo, portanto, ser identificadas e desenvolvidas pela gestão universitária. Como aporte teórico, foram utilizados os estudos de Perrenoud

Mestra em Administração pela Pontifícia Universidade Católica do Paraná; Especialista em Gestão Empresarial pelo Centro Universitário UniOpet.

2 Especialista em Gestão Empresarial pela Fundação Getulio Vargas; Mestrando em Administração pela Pontifícia Universidade Católica do Paraná

3 Doutora e Mestra em Educação pela Pontificia Universidade Católica do Paraná. 
(1998), Tardif (2000) e Shugurensky (2006), entre outros. Assim, o artigo explorou, por meio de um estudo de caso, quais são os fatores determinantes à construção das competências docentes na perspectiva dos professores. Os resultados revelaram que os professores atribuem à prática em sala de aula o maior diferencial na formação de suas competências, em detrimento dos fatores colaborativos e institucionais. Palavras-chave: Ensino superior. Competências docentes. Universidades particulares. Escola de negócios.

Abstract: Since the late 1990s, the demand for higher education in business administration has increased in Brazil, providing benefits to private universities. While this environment offers great opportunity for business schools, it also entails a number of challenging issues that impact the value chain of education. Understanding that people are the great differential of successful organizations, the objective of this article is to reflect on the need for private universities to seek in their teaching staff bases for competitive advantage. Based on the concept of professional competencies, it is argued that the competences of teachers are strictly related to their context of action and should therefore be identified and developed by university management. As a theoretical contribution the studies of Perrenoud (1998), Tardif (2000) and Shugurensky (2006) were used. Thus, the article explores, through a case study, the determining factors for the construction of teacher competencies from the perspective of teachers. The results showed that teachers attribute to classroom practice the greatest difference in the training of their competences, to the detriment of collaborative and institutional factors.

Keywords: Higher education. Teaching skills. Private universities. Business school.

Résumé: Depuis la fin des années 90, la demande d'enseignement supérieur en administration a augmenté au Brésil, offrant des avantages aux universités privées. Bien que ce cadre offre de grandes opportunités aux écoles de commerce, il implique également une série de questions complexes impactant sur la chaîne de valeur de l'éducation. Comprenant que les gens sont le grand différentiel des organisations prospères, cet article vise à réfléchir sur la nécessité pour les universités privées de rechercher dans le corps enseignant leurs bases pour un avantage concurrentiel. En se basant sur le concept de compétences professionnelles, on estime que les compétences des enseignants sont strictement liées à leur contexte de performance et devraient donc être identifiées et promues par la gestion universitaire. En tant que contribution théorique, les études de Perrenoud (1998), Tardif (2000) et Shugurensky (2006) ont été utilisées. Ainsi, l'article a exploré, à travers une étude de cas, quels sont les facteurs déterminants pour l'élaboration des compétences d'enseignement du point de vue des professeurs. Les résultats ont révélé que les enseignants attribuent à la pratique en classe le plus grand différentiel dans le développement de leurs compétences, au détriment des facteurs collaboratifs et institutionnels.

Mots-clés: Enseignement supérieur Compétences d'enseignement. Universités privées. École de commerce.

Recebido em 23 de novembro de 2018 Aceito em 1 de julho de 2019 Publicado em 20 de Agosto de 2019 


\section{INTRODUÇÃO}

As transformações econômicas, tecnológicas e sociais em curso têm trazido às organizações desafios nunca antes vivenciados. As universidades não estão imunes a essas influências, sendo alvo de crescentes exigências emanadas pelo setor produtivo e pela sociedade. Para permanecerem atuantes, as universidades têm buscado desenvolver estratégias que atendam a tais demandas econômicas e sociais, ao mesmo tempo em que lhes permitam resultados sustentáveis.

Em termos de gestão, a organização universitária assemelha-se a outros tipos de organizações, quer dizer, é fundamental que se volte para os fatores críticos do sucesso organizacional: competição, demanda, custos e pessoas. Entretanto, na balança dos fatores críticos das universidades, o fator "pessoas" tende a ter mais peso. Conforme descrito por Mintzberg (2006), a área acadêmica fundamenta-se no trabalho de profissionais altamente especializados, os quais atuam com base em sua competência profissional, em uma ocupação essencialmente qualitativa e individual.

A despeito do movimento de profissionalização do ensino superior, observa-se que, em diversas áreas do conhecimento, grande parte dos docentes não possui formação pedagógica (TARDIF, 2000). Ainda que a ideia de profissionalização do docente esteja bastante difundida, Tardif (2000) considerou que grande parte das competências docentes não pode ser previamente ensinada na formação inicial. lsso é ainda mais marcante em determinadas áreas que se mostram fortemente atreladas à prática profissional e ao mercado de trabalho. Esse é o caso da administração, definida como objeto de estudo aqui tratado. Assim, coube a esse estudo investigar como se constroem as competências do professor universitário no contexto das escolas de negócios.

Apesar da temática de competências não ser nova, sua discussão mostra-se ainda bastante relevante, tanto no ambiente acadêmico, quanto no organizacional. Para Fleury e Fleury (2004), o tema competência entrou para a pauta das discussões acadêmicas e empresariais principalmente por estar associado a diferentes instâncias de compreensão: nível das pessoas, nível das organizações e nível dos países (sistemas educacionais e formação de competências). Porém, é contraditório que, enquanto a gestão estratégica enfatiza que as competências são únicas e específicas de cada organização, a literatura gerencial tenha se desenvolvido com predominância de competências genéricas e transferíveis para a maioria das ocupações ou cargos (STASZ, 1997).

No que se refere às competências docentes e, de um modo geral, ao desenvolvimento de competências como tal, no caso específico do Brasil, vale a pena mencionar a existência de crítica à temática, sob o pressuposto de que não enfatiza a qualificação das pessoas como 
um processo histórico e social, atrelada que está aos interesses de organismos multilaterais na educação brasileira. No entanto, mesmo adotando-se a noção de competências docentes, hipótese deste artigo, há acentuada divergência entre teóricos acerca de como elas se caracterizam e como são formadas. A respeito, Tardif (2000) observa que essas competências são em grande parte personalizadas e situadas de maneira que não há como dissociá-los do contexto e das situações de trabalho.

0 objetivo deste estudo, portanto, foi analisar, por meio de uma pesquisa com abordagem qualitativa: como ocorre a construção das competências do professor de ensino superior de uma escola de negócios pertencente a uma instituição de ensino privada. Baseando-se em Perrenoud (1998), foram considerados três tipos de fatores que influenciam nessa construção dentro de um ambiente organizacional, sendo: Fatores individuais; Fatores colaborativos; e Fatores institucionais.

Os resultados encontrados demonstraram que, apesar do movimento de profissionalização docente ocorrido nas últimas décadas, o qual visou fixar padrões de competência e repertórios específicos para a atividade de ensino (TARDIF, 2000), os professores entrevistados atribuem à prática em sala de aula o maior diferencial na formação de suas competências. $A$ validade deste estudo está em demonstrar que, embora a carreira docente seja fortemente atrelada ao mérito e ao esforço individual, outros fatores do ambiente acadêmico podem contribuir para o desenvolvimento das competências docentes. Considera-se que a valorização desses fatores possibilita o aperfeiçoamento de competências relevantes para a estratégia organizacional e a sustentabilidade das universidades particulares inseridas dentro do contexto descrito.

Após esses dados introdutórios, nos tópicos seguintes são apresentadas considerações teóricas sobre a realidade do ensino superior, competências profissionais e competências docentes. A seguir, descrevem-se a metodologia do estudo e os resultados da pesquisa para, por fim, apontar as considerações finais.

\section{REFERENCIAL TEÓRICO}

\subsection{A NOUA REALIDADE NO ENSINO SUPERIOR E A PROFISSIONALIZAÇÃO DO ENSINO}

0 ambiente no qual se inserem as organizações de ensino superior vem passando por mudanças importantes, provocadas principalmente por expectativas sociais, políticas 
públicas e inovações tecnológicas (GUMPORT; SPORN, 1999). Esse cenário em transformação criou um conjunto de desafios sem precedentes para as universidades (SCHUGURENSKY, 2006).

No Brasil, o marco dessas mudanças foi a publicação da Lei de Diretrizes e Bases da Educação Nacional (Lei n. 9.394/1996), a qual permitiu que as instituições de ensino superior ampliassem a oferta de vagas (INSTITUTO NACIONAL DE ESTUDOS E PESQUISAS EDUCACIONAIS ANISIO TEIXEIRA, 2015). Aliada a isso, a incapacidade do poder público em atender à demanda por educação superior oportunizou que o setor privado assumisse $87,5 \%$ da participação desse mercado (INSTITUTO NACIONAL DE ESTUDOS E PESQUISAS EDUCACIONAIS ANÍSIO TEIXEIRA, 2015). Contudo, nos últimos anos, as universidades privadas brasileiras vêm enfrentando uma crise financeira causada por diversos fatores, como:

a. diminuição de financiamentos do governo aos estudantes;

b. delegação da responsabilidade na gestão para o nível institucional;

c. competição por alunos e recursos;

d. pressões governamentais para melhorar a qualidade no ensino e aprendizagem;

e. alteração na demografia dos alunos;

f. novas tecnologias de ensino como a educação a distância.

Esse quadro imprimiu aumento de competitividade ao setor, permitindo, em um primeiro momento, o ingresso de estudantes a taxas crescentes anualmente (SCHUGURENSKY, 2006). Posteriormente, o efeito colateral dessa competição refletiu em excesso de oferta de vagas para cursos de graduação, o que gerou uma série de consequências "em cascata", como fechamento de turmas, pressão nos preços das mensalidades e problemas nas estruturas de custos das instituições (INSTITUTO NACIONAL DE ESTUDOS E PESQUISAS EDUCACIONAIS ANÍSIO TEIXEIRA, 2015).

De acordo com Meyer e Murphy (2003), outro aspecto que a Lei n. 9.394/1996 reforçou foi a preocupação com a qualidade do ensino ministrado em universidades brasileiras, juntamente com fortes alterações do mercado de trabalho e com o surgimento de novas profissões, que passaram a demandar habilidades diferenciadas dos profissionais recémformados. No entanto, acrescentam, o que se observou nos últimos anos é que muitas instituições de ensino superior não conseguiram corresponder a tais exigências, gerando questionamentos por parte dos setores produtivos acerca da qualidade da formação universitária, bem como críticas sobre a chamada "mercantilização" do ensino (MEYER; MURPHY, 2003). 
No campo da formação e do ensino da administração, Nassif, Hanashiro e Torres (2010) afirmaram que, no mundo dos negócios, as exigências tornaram-se mais complexas e dinâmicas, em decorrência do aumento da interdependência entre empresas, setores e países. Esse fenômeno levou profissionais e organizações a refletirem intensamente acerca das competências necessárias para atuar em mercados tão competitivos (NASSIF; HANASHIRO; TORRES, 2010). No caso da graduação em administração, Hawawini (2005) citou que um curso típico nessa área é projetado para transmitir uma grande dose de técnicas analíticas e de gestão quantitativa. Hawawini (2005) observou, porém, que profissionais, ex-alunos e estudantes de administração vêm exigindo cada vez mais as chamadas soft skills de dois tipos: comportamental e social. Nas habilidades comportamentais, o autor incluiu a capacidade de trabalhar com os outros, de se comunicar de forma eficaz, de demonstrar consciência multicultural e de exibir algumas qualidades empreendedoras e de liderança (HAWAWINI, 2005). Já as habilidades (ou valores) sociais referem-se à capacidade de tomar decisões de negócios com ética, levando em conta a responsabilidade social corporativa e o desenvolvimento sustentável (HAWAWINI, 2005).

Tais exigências vêm demonstrando que os conhecimentos proporcionados pelos currículos não valem por si mesmos, mas pela possibilidade de auxiliarem no desenvolvimento das competências de cada estudante e de serem, por este, investidos na ação profissional (ESTEVES, 2009). Por outro lado, a lógica da competência coloca as próprias instituições de ensino à prova perante a sociedade, forçando-as a reverem como suas práticas educacionais e os conteúdos ensinados lidam com as novas demandas sociais (RICARD0, 2010).

Apesar do crescimento e da importância que a educação superior apresenta no mercado de trabalho (NASSIF; HANASHIRO; TORRES, 2010), a ampliação de acesso não resultou em uma formação que atenda plenamente aos projetos pessoais e coletivos (RICARD0, 2010). Nesse sentido, ainda existe muito a ser feito em sala de aula, evidenciando o papel das práticas docentes na formação superior. Nassif, Hanashiro e Torres (2010, p. 366) ressaltam que na realidade do ensino superior brasileiro,

[...] o professor tem se mostrado figura importante e determinante no êxito ou fracasso do processo educativo no contexto da universidade. Sobre ele recai grande responsabilidade quanto aos resultados esperados, sobretudo no que diz respeito à formação de profissionais que atuam no mercado de trabalho.

Acerca desse contexto, Tardif (2000) destacou a profissionalização do ensino e da formação para o ensino como uma vasta corrente de ações, políticas públicas e reformas que constituíram um movimento quase internacional ocorrido na década de 1990. Para Tardif (2000), esse fato representou uma tentativa de reformulação epistemológica do ofício do professor, 
com o objetivo de fixar padrões de competência e repertórios de conhecimentos específicos à atividade de ensino.

Embora a profissionalização do ensino tenha despontado como um movimento para impulsionar a educação para a melhoria da qualidade, Tardif (2000) observou que grande parte dos saberes dos professores não pode ser previamente enquadrada, pois possuem algumas características distintas. Em primeiro lugar, os saberes dos professores são temporais, o que quer dizer que são edificados por meio da experimentação e da prática. A segunda característica refere-se a que os saberes dos professores são plurais e heterogêneos. Nesse sentido, são provenientes de diversas fontes e empregados com diferentes objetivos, assumindo seu significado na ação. Por fim, os saberes dos professores são personalizados e situados, no sentido de que são apropriados e incorporados, sendo, portanto, difíceis de dissociar dos profissionais e das situações de trabalho (TARDIF, 2000).

As características apontadas por Tardif (2000) revelam que tanto os saberes quanto as competências dos docentes precisam ser constantemente analisados e remodelados, de maneira a se adaptarem ao contexto do ensino. Assim, a profissionalização do ensino não representa um fim em si, mas uma resposta à complexidade das situações, das expectativas e das relações educativas (PERRENOUD, 2000). No que tange ao ensino superior, as enormes transformações ocorridas não permitem mais um ensino estereotipado. Para Perrenoud (1998, p. 221), as situações de ensino-aprendizagem nos ambientes contemporâneos exigem "[...] estratégias originais e sob medida partindo da análise do que foi adquirido, das necessidades, dos recursos e das forças hic et nunc."

Dessa forma, uma perspectiva de profissionalização do ensino deve fortalecer a reflexão dos próprios professores acerca de sua atuação. Além disso, o acolhimento desse movimento demanda a atuação integrada de professores, tanto em nível individual, quanto coletivo (interação com os pares), bem como das instituições educacionais.

\subsection{COMPETÊNCIAS PROFISSIONAIS}

As grandes transformações no contexto do trabalho, em curso desde a década de 1990, implicaram em mudanças na forma de olhar as pessoas nas organizações (FERNANDES, 2013). 0 questionamento acerca da organização funcional do trabalho e das estruturas organizacionais rígidas possibilitou um entendimento das pessoas mais por sua contribuição para o contexto organizacional do que por seus cargos ou posições no organograma (FERNANDES, 2013). Feuerschütte e Godoi (2011) apontaram que a mudança da lógica do posto de trabalho representou um movimento social e histórico, o qual destacou a 
temática da competência tanto na pesquisa quanto na prática organizacional. Feuerschütte e Godoi (2011) argumentaram, ainda, que a necessidade de repensar a relação entre os saberes profissionais e as demandas dos processos de trabalho e das organizações fortaleceu o discurso de competência em diversos setores.

A despeito da consolidação da "lógica da competência" (RICARDO, 2010), diversos autores forneceram visões críticas acerca do conceito de competência, especialmente quando deslocado do setor produtivo para o universo pedagógico. Embora o modelo de competências se baseie no desenvolvimento de habilidades cognitivas e comportamentais - as quais parecem responder melhor à automatização e às crises - ele seria excessivamente voltado para a pessoalidade dos indivíduos, como explica Ricardo (2010). Nessa perspectiva, a noção de competência não percebe a qualificação como um processo histórico e social, enfraquece as conquistas coletivas e acaba por liberar o Estado de regulamentações. Assim, interesses pessoais e coletivos são colocados em conflito nas relações entre empregado e empresa.

Acerca do campo de gestão de pessoas, Fleury e Fleury (2004) observaram que o desenvolvimento das competências organizacionais foi relacionado ao aperfeiçoamento das competências individuais, bem como às condições fornecidas pelo contexto. A esse respeito, Ruas, Antonello e Boff (2005) destacaram a importância de trabalhos de autores franceses e canadenses na construção de uma perspectiva orientada às competências individuais. Nessa perspectiva, a competência só existe para um sujeito e em um determinado contexto, portanto é um conceito que se realiza na ação (FEUERSCHÜTTE; GODOl, 2011).

Embora as competências individuais estejam fundamentadas especialmente em conhecimentos, Fleury e Fleury (2004) argumentaram que elas são aprimoradas conforme a necessidade do profissional para melhorar seu desempenho no trabalho. Assim, a competência profissional de um indivíduo surge como um saber agir responsável e reconhecido pelos demais (FERNANDES, 2013). Como um saber em ação, a competência representa a capacidade de um indivíduo mobilizar, integrar, transferir conhecimentos, recursos, habilidades de maneira pertinente a um determinado contexto profissional (FLEURY; FLEURY, 2004; EGRY; MARQUES; FONSECA, 2006; BONFIM, 2012). Feuerschütte e Godoi (2011) ressaltaram que esses recursos mobilizados são inseparáveis de sua personalidade, sendo, portanto, heterogêneos e irregulares.

Le Boterf (1994) situou a competência profissional como resultante do cruzamento de três eixos: o primeiro refere-se à formação da pessoa (sua biografia e sua socialização), o segundo é caracterizado por sua formação educacional, e o terceiro é representado por sua experiência profissional.

No que tange ao contexto da atuação, Le Boterf (1994) propôs que as competências individuais se originam a partir de três fatores: o saber agir, por meio do qual o profissional deve saber ir além do que lhe é prescrito, o querer agir, que se refere a sua motivação e poder 
agir, atribuído à situação profissional na qual o indivíduo está inserido, contemplando suas responsabilidades, riscos e deveres (Figura 1). Nesse sentido, uma característica essencial da competência profissional consiste no conjunto de escolhas e combinações que um indivíduo realiza com seus próprios recursos, com o intuito de atingir os objetivos determinados pelo contexto ou organização em que atua (FEUERSCHÜTTE; GODOl, 2011).

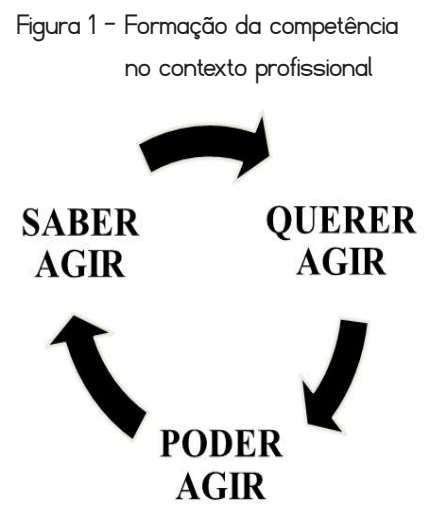

Fonte: adaptada de Le Boterf (1994).

Dessa forma, a competência individual insere-se em uma perspectiva construtivista, modelada tanto pelo indivíduo, quanto pelo contexto em que ele atua, podendo, portanto, ser aperfeiçoada e corrigida (MOURA; BITENCOURT, 2006; BONFIM, 2012). Diferente do conceito de cargo, a perspectiva da competência possibilita ao indivíduo oferecer respostas diante de situações não rotineiras e imprevisíveis (MOURA; BITENCOURT, 2006).

\subsection{COMPETÊNCIAS NA DOCÊNCIA DE ENSINO SUPERIOR}

A institucionalização da noção de competência nos ambientes educacionais apontou que, a despeito das críticas da sociologia do trabalho, "não se trata de um mero efeito de moda, mas aponta mudanças sociais significativas." (RICARD0, 2010, p. 623). Nesse sentido, a abordagem de competências pode, sob o entendimento de Perrenoud (1998, 2000), representar uma possível alternativa para adequação das instituições de ensino às mudanças sociais e econômicas.

No contexto educacional, Nassif, Hanashiro e Torres (2010) argumentaram que a noção de competência é propícia e abrangente, especialmente por se embasar no conceito de pessoalidade. Esse conceito, segundo os autores, caracteriza o saber do professor por 
meio de seu significado pessoal, por seu contexto de atuação, bem como por sua pertinência à situação (NASSIF; HANASHIRO; TORRES, 2010).

Acerca desse contexto, Perrenoud e Thurler (2009, p. 19) observaram que

\begin{abstract}
o reconhecimento de uma competência [no trabalho do docentel não passa apenas pela identificação de situações a serem controladas, de problemas a serem resolvidos, de decisões a serem tomadas, mas também, pela explicitação de saberes, das capacidades, dos esquemas de pensamento e das orientações éticas necessárias.
\end{abstract}

Esse segundo rol de recursos docentes, denominado pelos autores de “microcompetências" (PERRENOUD; THURLER, 2009), é em grande parte construído ao longo da prática, por meio da acumulação ou da formação de novos esquemas de ação.

Perrenoud e Thurler (2009) defendem que uma formação inicial é capaz de fornecer os conhecimentos fundamentais de uma determinada área do saber, além de desenvolver as competências básicas do docente e treiná-lo para que possa utilizá-las. No entanto, eles argumentaram que a maior parte das competências dos professores não pode ser facilmente dissociada das finalidades do sistema educacional em que estão inseridas (PERRENOUD; THURLER, 2009). Nesse sentido, a discussão puramente técnica sobre a formação e as competências dos professores é, segundo Perrenoud e Thurler (2009), ilusória. É fundamental, portanto, considerar que as práticas docentes se tornam e se modificam no curso da ação do professor universitário em seu contexto. Para que mudanças favoráveis ocorram, porém, os docentes necessitam de apoio institucional em sua formação continuada e em relação às suas condições de trabalho.

A esse respeito, Nassif, Hanashiro e Torres (2010, p. 365) afirmaram que do professor "[...] cobra-se a necessidade de formar alunos capacitados para enfrentar as exigências de mercado, sem, contudo, haver reflexão mais profunda sobre quais são e como esses professores desenvolvem suas competências." Perrenoud (1998) alegou que, embora soe como uma política óbvia, um dos maiores desafios para instituições de ensino é colocar explicitamente a formação contínua a serviço do desenvolvimento das competências profissionais. Perrenoud (1998) defendeu, ainda, que o desenvolvimento das competências individuais dos docentes possibilita a ampliação do campo de trabalho, além de dar às práticas reais mais espaço que aos modelos prescritivos (competências genéricas) e aos instrumentais. Assim, entende-se que para que práticas docentes evoluam e atendam às profundas mudanças enfrentadas pelo setor de educação no País, é fundamental que as universidades reconheçam as condições e as limitações do trabalho real de seu corpo docente. 
A respeito da área da administração, Bouchikhi e Kimberly (2001) acrescentaram que as grandes transformações em curso nas organizações e na pesquisa gerencial exigem mudanças na forma como as instituições de ensino superior pensam, executam e avaliam o trabalho docente. Bouchikhi e Kimberly (2001, p. 78) foram imperativos ao afirmar que "[...] assim como nas empresas, a pesquisa e ensino em administração e educação empresarial devem inovar ou morrer."

Entendendo serem as pessoas o grande diferencial das organizações bemsucedidas, aponta-se, portanto, a necessidade de as universidades buscarem no corpo docente suas bases para a vantagem competitiva. Se por um lado forças externas têm forçado as universidades a enfrentarem uma realidade complexa, ainda é no ambiente interno de ensino (salas de aula ou salas virtuais) que podem realizar sua maior vocação organizacional. Assim, dada a importância dos docentes nesse quadro e tendo em consideração que suas competências são estritamente relacionadas ao seu contexto de atuação, é oportuno que elas sejam identificadas e desenvolvidas pela gestão universitária. Essa situação manifestase premente em algumas áreas do conhecimento, nas quais as transformações do contexto se fazem sentir com mais força, como é o caso das escolas de negócios.

Entretanto, Nassif, Hanashiro e Torres (2010) argumentaram que em grande parte das vezes, a discussão sobre a competência de professores privilegia a valorização da titulação em detrimento do saber. Em contrapartida, Perrenoud (1998, p. 208) argumentou que o desenvolvimento de competências acontece ".... quase sempre para além da formação contínua, no foro íntimo dos professores e, eventualmente, no de uma equipe pedagógica." 0 autor também observou que a formação continuada dos docentes pressupõe "ampliar o campo de trabalho e dar às práticas reais mais espaço que aos modelos prescritos e aos instrumentais." (PERRENOUD, 1998, p. 208). No caso do Brasil, observa-se um movimento em curso de busca de titulação acadêmica, com vistas a atender às exigências dos órgãos oficiais. Porém, conforme a discussão apresentada procurou demonstrar, são diversos os fatores que vão influenciar as competências do professor, como sua identidade profissional, seus conhecimentos e o contexto em que atua.

\section{METODOLOGIA DA PESQUISA}

Diante da discussão teórica apresentada, a coleta dos dados buscou identificar os fatores que contribuem para a construção das competências do professor universitário no contexto de mudanças na educação superior e a maneira como isso ocorre. Trata-se de uma pesquisa exploratória, de abordagem qualitativa (RICHARDSON, 2008), que teve por objetivo reconhecer na prática docente elementos que possibilitem análise reflexiva e crítica 
acerca das competências dos professores e sobre como são construídas (TARDIF, 2000). Baseando-se em Perrenoud (1998), o estudo considerou três eixos de fatores relacionados ao desenvolvimento de competências: Fatores individuais; Fatores colaborativos (pares); e Fatores institucionais. Esses fatores foram empregados como categorias analíticas do estudo, as quais foram vinculadas ao construto "construção das competências". De maneira a orientar a coleta dos dados, esses fatores embasaram a elaboração do roteiro para entrevistas com professores universitários.

Para os fatores individuais, as entrevistas levantaram como os professores tomaram consciência de suas competências docentes e como estruturaram sua prática profissional (TARDIF, 2000). Dessa forma, investigou-se como os docentes construíram suas certezas, truques, rotinas e modelos, bem como onde (ou em quem) buscaram suas referências. Com relação a fatores colaborativos, o objetivo foi verificar se existe colaboração e troca de informações intencionais entre os pares (colegas professores) e de que maneira elas contribuem na construção das competências docentes. Sobre fatores institucionais, a pesquisa apurou se na universidade em estudo existem ações que proporcionam o diálogo sobre as finalidades e objetivos educacionais da instituição e como elas influenciam nas atitudes e identidades profissionais. Além disso, buscou-se conhecer se a instituição oferece modalidades de formação contínua ou outros empreendimentos coletivos a serviço da formação docente.

No que tange à metodologia, a estratégia de pesquisa adotada foi o estudo de caso, a partir dos conceitos de Yin (2004). A instituição selecionada foi uma universidade privada sem fins lucrativos, localizada no estado do Paraná. A organização foi escolhida em razão da acessibilidade dos pesquisadores aos entrevistados. Trata-se de uma instituição de renome no cenário nacional, tanto em relação à qualidade do ensino, quanto à reputação de seus professores. Em termos de classificação, a Universidade foi recentemente qualificada como a melhor instituição privada de ensino do Estado do Paraná, enquanto que, no cenário nacional, ocupa posição de destaque na relação das melhores (TIMES HIGHER EDUCATION, 2016). Conforme o interesse delineado no referencial teórico acerca da área de ensino em Administração, o estudo concentrou-se na Escola de Negócios dessa Universidade.

Os dados do estudo se caracterizaram como primários, e sua coleta ocorreu por meio de entrevistas semiestruturadas, realizadas com dois professores titulares da graduação regular em administração (modalidade presencial) e um ex-professor do mesmo curso que, no momento da pesquisa, ocupava cargo no setor administrativo da instituição. As entrevistas duraram em média 30 minutos, tendo sido gravadas e literalmente transcritas. Foi assegurado aos entrevistados o sigilo em relação aos seus nomes e dados pessoais que permitissem identificação. A definição de quais professores seriam entrevistados buscou contemplar docentes em distintos momentos da carreira, com o intuito de ampliar a variedade 
de informações acerca de suas vivências. 0 roteiro das entrevistas englobou questionamentos sobre os três eixos de fatores de desenvolvimento de competências, descritos anteriormente.

Para a análise dos dados, foi utilizado o método de análise temática, conforme proposto por Braun e Clarke (2006). Dentro da perspectiva da análise temática, foram empregadas as três categorias analiticas, previamente definidas, de acordo com os objetivos específicos da pesquisa apresentados no início desta seção.

\section{APRESENTAÇÃO E ANÁLISE DOS DADOS}

\subsection{CARACTERIZAÇÃO DOS ENTREUISTADOS}

As entrevistas realizadas orientaram-se por um recorte temporal, o qual buscou se ater aos elementos e fatos que influenciaram no desenvolvimento das competências dos docentes no contexto específico da Universidade pesquisada. Porém, considerando que as competências dos docentes são construídas no decorrer de suas experiências de vida e de suas atuações profissionais (LE BOTERF, 1994; TARDIF, 2000), considerou-se importante caracterizar previamente a trajetória de cada um dos docentes que participaram do estudo.

Docente 1: graduou-se em Matemática (licenciatura) em 1994, iniciando sua trajetória na docência logo no ano seguinte. Inicialmente, havia atuado no ensino médio, migrando para o ensino universitário a partir do ano 2000. Em 2001, ingressou no Mestrado em Tecnologia e Sociedade e, no mesmo ano, passou a atuar como docente na Universidade pesquisada. Além do Mestrado, o Professor possui o título de Doutor em Administração, obtido na Escola de Negócios da mesma lnstituição. Desde sua graduação até a ocasião da pesquisa, o Docente manteve dedicação exclusiva ao ensino.

Docente 2: graduado em Marketing e Direito em 2009, posteriormente fez uma especialização em Marketing. Antes de iniciar na carreira docente, atuava profissionalmente na Área de Marketing na mesma Instituição pesquisada, tendo sido convidado, em 2013, pela Escola de Negócios para ministrar uma disciplina na graduação. Desde então, divide suas atividades profissionais entre a docência e o cargo executivo na lnstituição.

Docente 3: graduou-se em Jornalismo em 2005 e, a seguir, fez uma especialização em Relações Internacionais. Atuou na docência no ensino superior da Escola de Negócios por quase três anos e dividiu seu tempo com outras atividades profissionais ligadas à 
comunicação em rádio. Embora tenha deixado a atuação docente, atualmente desempenha uma função como executivo na área de comunicação da Universidade estudada.

\subsection{CONSTRUÇÃO DAS COMPETÊNCIAS DOS PROFESSORES UNIUERSITÁRIOS}

\subsubsection{Fatores individuais}

Docente 1: com relação aos fatores individuais, o elemento mais significativo em sua fala foi considerar ser necessário ao docente "ter vontade" de estar em sala de aula e de "despertar no aluno aquela virada de chave sobre alguma matéria." (informações verbais). Pela perspectiva teórica de competências empregada neste estudo, a capacidade de um indivíduo em entregar um valor para uma organização passa pelo querer agir (LE BOTERF, 1994). Além de abranger aspectos motivacionais, o conceito querer agir está associado aos fatores individuais, pois favorece a tomada de consciência acerca das próprias competências (PERRENOUD, 1998). A esse respeito, o Professor explicou que sempre teve convicção de que seguiria na carreira docente e que isso o ajudou muito a buscar conhecimentos e desenvolver competências para sua atuação.

Tomando a concepção construtivista das competências docentes (MOURA; BITENCOURT, 2006), o saber agir aparece como um aspecto diretamente relacionado ao querer agir. Isso porque o saber agir contempla não apenas os conhecimentos já adquiridos, mas também como estes são aperfeiçoados para melhorar seu desempenho profissional ou de acordo com as necessidades emergentes no contexto (FLEURY; FLEURY, 2004). Relacionado a isso, o Professor descreveu como sua própria identidade mudou ao longo da carreira, indicando que o surgimento das metodologias ativas foi um elemento importante para essa mudança. Ele explicou que, em seu bacharelado, foi formado para dar aulas expositivas, mas que, com as metodologias ativas, passou a entender que "o foco na sala de aula é no feedback." (informação verbal).

Outro ponto representativo na fala do Docente foi o aspecto reflexivo da profissão, pelo qual, por duas vezes em sua carreira, reconheceu ter tido condutas "inadequadas" junto aos alunos. Retomando Perrenoud e Thurler (2009), tal processo reflexivo descrito pelo Docente reflete a noção de "microcompetências" por eles apresentada. Nesse sentido, a prática profissional não apenas possibilita ao profissional construir seus esquemas de ação, mas também reconstruí-los quando julgar necessário. 
Docente 2: o Profissional contou que atuar na docência sempre havia sido um sonho, mas que o início de sua carreira na área aconteceu por coincidência, pelo fato de estar trabalhando em uma instituição de ensino. Do ponto de vista de fatores individuais, o Docente também valorizou o querer agir (LE BOTERF, 1994), tanto pelo aspecto motivacional, quanto pela tomada de consciência de suas competências (PERRENOUD, 1998). Assim, o entrevistado explicou que teve de buscar conhecimento sozinho, em decorrência de a docência ter entrado subitamente em sua vida. Ele mencionou que, quando começou a atuar, passou a "entender o lado do professor" (informação verbal), referindo-se à perspectiva pedagógica necessária à profissão.

Em alguns momentos o Profissional correlacionou o desenvolvimento das competências à prática profissional, como, por exemplo, a percepção acerca dos "alunos estarem absorvendo o que o professor está falando", ao que denominou "processo empírico" (informações verbais). Embora a literatura reconheça que as competências profissionais possam ser aprimoradas conforme a necessidade do indivíduo em melhorar seu desempenho, considera-se que a principal base para esse desenvolvimento é o conhecimento (FLEURY; FLEURY, 2004). Apesar de o Docente 2 valorizar seu querer agir (aspectos motivacionais e tomada de consciência de suas capacidades), ficou evidenciada em sua fala uma sensação de carência de conhecimentos pedagógicos fundamentais. Assim, ao ser questionado se acreditava que uma preparação anterior teria the auxiliado, ele disse acreditar que sim. Mencionou, ainda, que a formação pedagógica teria the dado um "diferencial", especialmente sobre "questões do dia a dia" da sala de aula, como "dificuldades de aprendizagem" e "conflitos em sala". Embora o Professor tenha buscado emular referências de bons professores seus no passado, reforçou que nenhuma delas o auxiliou a suprir essas "demandas pedagógicas" (informações verbais).

Docente 3: o Profissional relatou que procurou a docência com objetivos de complementar seus conhecimentos, entrar em contato com um público diferenciado e receber novos conhecimentos por parte dos estudantes. Na ocasião da docência, ministrou aulas de comunicação na Escola de Negócios. Relatou que apesar de ter sentido um "impacto inicial" por estar em sala de aula, sentiu que sua contribuição para o curso era bastante proveitosa, pois sabia que os próprios estudantes haviam solicitado a presença de um professor com experiência de mercado.

Ao retomar seu início na docência, o Profissional destacou sua carga de conhecimentos técnicos em comunicação e negócios e como estes seriam válidos para o trabalho docente. Por outro lado, mencionou ter se sentido um pouco "amedrontado" com os questionamentos dos alunos acerca do conhecimento por ele apresentado. Apesar disso, ressaltou que entende que muitas vezes tais questionamentos surgem com o objetivo de gerar discussão, principalmente pelo fato de que na Escola de Negócios existem muitos 
estudantes com faixa etária mais elevada e que também atuam no mercado. Considerou, porém, que esse perfil fazia com que em muitas turmas surgissem discussões e conflitos "morosos" (informações verbais).

Ao ser questionado sobre como desenvolveu competências para atuar com essas situações em sala, o Profissional disse não ter conseguido "encontrar uma fórmula" que pudesse auxiliá-lo. Ele destacou também não ter conseguido lidar com alunos "desinteressados", os quais veem no professor um "inimigo". Por outro lado, ressaltou que sempre se deu bem com os alunos dedicados e com os mais velhos e que, aos poucos, foi percebendo que podia cobrar desempenhos diferentes de cada "tipo" de aluno (informações verbais).

De acordo com Feuerschütte e Godoi (2011), a competência de um profissional se caracteriza pelas escolhas e combinações que ele faz a partir de seus próprios recursos e que visam a atingir os objetivos e entregar valor para um grupo ou organização. Nesse quadro, ao se analisarem os fatores individuais do Docente 3, observa-se que suas competências docentes foram desenvolvidas principalmente a partir de seus conhecimentos técnicos e vivência em negócios, com o intuito de suprir a demanda dos estudantes justamente por esse tipo de conhecimentos. Considerando o cenário educacional de grande heterogeneidade nas salas de aula, uma das exigências para o professor torna-se a prática reflexiva, a qual pode o auxiliar na reflexão sobre suas experiências (RICARD0, 2010). Embora o Docente 3 tenha revelado dificuldade em trabalhar com a heterogeneidade de seus estudantes, a prática reflexiva the possibilitou desenvolver estratégias diferenciadas para cada "tipo" de aluno.

\subsubsection{Fatores colaborativos}

Docente 1: sobre os fatores colaborativos, o docente afirmou ter aprendido com colegas, especialmente os mais experientes. A esse respeito, Perrenoud (1998) argumentou que é fundamental para uma cultura profissional docente a existência de uma reciprocidade crítica, a qual possibilita aos profissionais tomarem as críticas de seus pares como forma de aperfeiçoar suas práticas, sem gerar mal-estar ou conflito.

Porém, de acordo com o Docente 1, a colaboração entre seus pares foi sempre muito pontual e informal, pois, segundo ele, grande parte dos colegas são "introspectivos" (informação verbal).

Além disso, o Docente disse acreditar que muitos de seus pares não se interessam muito em desenvolver novas competências no cenário em transformação da sala de aula. Com relação ao surgimento de metodologias ativas, por exemplo, ele mencionou que tais 
colegas tiveram maiores dificuldades em reinterpretar suas práticas e seus papéis em sala. Assim, muitos ainda mantêm concepções pedagógicas tradicionais, descritas pelo docente como: "se tiver que reprovar o aluno, reprova." (informação verbal).

Docente 2: acerca dos fatores colaborativos, o Docente relatou existirem poucos contatos de cooperação profissional entre os pares. Ele apresentou uma postura crítica em relação aos colegas, pelo fato de que muitos, segundo ele, ainda têm uma postura excessivamente expositiva e disseminam conteúdos antiquados. Ele relacionou essa postura docente à evasão escolar, pois acredita que os estudantes não conseguem perceber valor nas aulas.

A similaridade nas descrições do Docente 1 e do Docente 2 revela o que Perrenoud (1998) caracterizou como um dos obstáculos à profissionalização da docência. Para o autor, a profissionalização de um ofício resulta justamente da autonomia de um profissional em escolher seus métodos e meios de ação, permitindo-lhe fazer-se responsável por suas decisões (PERRENOUD, 1998). Porém, mudanças nas condições de ensino, bem como a emergência de novas práticas didáticas podem agravar a heterogeneidade já típica entre os professores. Assim, conforme menciona Perrenoud (1998, p. 220), alguns professores poderão permanecer "abandonados a si próprios". Nesse sentido, os fatores colaborativos no aperfeiçoamento das competências docentes possibilitam o fortalecimento de uma cultura de autoavaliação e, consequentemente, uma prática reflexiva, tanto individual quanto coletiva.

Docente 3: em relação aos fatores colaborativos, o Docente descreveu que sempre houve uma cobrança pela coordenação de seu curso para que os professores mantivessem contato frequente, com o objetivo de elaborar atividades que envolvessem duas ou mais disciplinas. Segundo ele, a proposta pedagógica da coordenação era simular uma atuação de mercado, na qual os saberes precisavam estar integrados. Além de benefícios para o aprendizado dos estudantes, tal proposta estimula a interação e cooperação entre os professores do curso, despertando a sinergia entre o desenvolvimento pessoal e o trabalho coletivo (PERRENOUD, 1998). Assim, o contato aberto com os colegas representava um importante fator colaborativo para o desenvolvimento de competências.

Em termos pedagógicos, o Profissional contou ter aproveitado em suas aulas "modelos" de outros docentes. Também informou que o contato com colegas auxiliou na resolução dos conflitos em sala de aula, pois, em diversos casos, outros professores relataram problemas similares aos dele e até mesmo com os mesmos alunos. Ele relatou que esse contato the trazia um "alívio" (informações verbais). Apoiado em Perrenoud (1998), observa-se como a interação entre professores favorece a prática refletida e, consequentemente, a profissionalização. 


\subsubsection{Fatores institucionais}

Docente 1: com relação aos fatores institucionais, o Professor indicou a questão das metodologias ativas como uma forma de a universidade se aproximar dos estudantes, bem como do mercado e das mudanças no campo da administração. Porém, o Professor não reconheceu a existência de ações ou esforços institucionais que tenham the apoiado no desenvolvimento das competências. Na questão das metodologias ativas, por exemplo, embora a implementação tenha ocorrido de forma gradual, o Profissional considerou que sua eficácia fica muito a cargo do professor. De maneira similar, Perrenoud (1998) observou que embora as instituições educacionais sejam encarregadas de possibilitar a formação continuada dos professores, caberá a eles inscrever os conhecimentos e informações adquiridos em uma perspectiva pedagógica e didática. Isso porque uma competência é um saber mobilizar, que permite ao individuo enfrentar com eficácia situações complexas ou inéditas (FLEURY; FLEURY, 2004; PERRENOUD, 1998).

Nesse sentido, o Docente colocou-se de maneira bastante protagonista em relação à formação dos discentes da Escola de Negócios, considerando o contexto de mudanças. Para o Professor, a formação dos estudantes é "um desafio grande" porque é "impossível trazer para eles o conhecimento científico, sem tentar refletir o que acontece no mercado." (informação verbal).

Docente 2: sobre os fatores institucionais, o professor disse não se lembrar de nenhum mecanismo da coordenação ou da Universidade que favorecesse o desenvolvimento de suas competências docentes. Ele mencionou haver dificuldade com relação ao Ministério da Educação (MEC) e a definição dos conteúdos que devem ser ministrados na graduação. De maneira geral, os objetivos da formação superior no Brasil são inúmeros e audaciosos, sendo improvável alcançar a todos. A esse respeito, Perrenoud (1998) observou que, conscientemente ou não, os professores precisam fazer adaptações ou improvisações tanto nos conteúdos quanto na forma de ensino. Nesse processo, os professores adotam determinadas prioridades considerando: os alunos que têm diante de si; suas competências e convicções pessoais; e as concepções pedagógicas que prevalecem entre seus colegas (PERRENOUD, 1998).

Acerca disso, o Docente 2 declarou achar que o currículo proposto pelo MEC é bastante "engessado", pois não permite "personalizações" por parte dos professores. Ao mesmo tempo, disse acreditar que, apesar de limitado, o currículo do MEC não deveria ser uma "muleta para o mau professor." (informações verbais). Observe-se que esse Professor desconhece que a proposta curricular do MEC, por meio das Diretrizes Curriculares Nacionais para cada curso de graduação, traz orientações e diretrizes, mas não uma "grade" curricular, como ocorria na legislação anterior. 
Docente 3: acerca dos aspectos institucionais, o Profissional disse acreditar que não havia estímulo da Universidade e da coordenação para que os professores trocassem informações além daquelas estritamente relacionadas às disciplinas. Para ele, todo esse processo de conversas e colaboração acontecia "por sorte mesmo, pois era tudo fora do horário." (informação verbal). Aqueles interessados em se desenvolver por meio desse contato deveriam usar mais seu próprio tempo (não remunerado). Para Perrenoud (1998), uma das condições institucionais importantes no desenvolvimento das competências docentes é a acepção da jornada de trabalho como mais vasta do que o período de presença em sala de aula. Além dos momentos para formação continuada, o tempo formalizado para ampliar os fatores colaborativos pode ser essencial para o progresso das competências do corpo docente.

Ao ser questionado se voltaria a atuar na graduação em Administração, o Profissional respondeu que não, justificando que o ambiente da graduação the gerou "frustração". Explicou que sente poder contribuir com muita coisa oriunda de sua experiência de mercado, porém acredita que na graduação não tem necessariamente uma "resposta dos estudantes" (informações verbais). Atualmente, ele faz parte do corpo docente de um curso de especialização em negócios e atua de maneira esporádica. Ele concluiu dizendo que, na especialização, percebe que o conhecimento é mais bem absorvido.

\section{CONSIDERAÇÕES FINAIS}

No contexto de grandes mudanças e competitividade no setor de educação superior, as universidades precisam se manter ativas para responderem às exigências sociais, econômicas e educacionais que vêm recebendo. Embora grande parte das instituições de ensino tenha incorporado inovações tecnológicas mediando o processo de ensinoaprendizagem, não se observou, pelos dados levantados neste estudo, o mesmo nível de atenção na qualificação do corpo docente. A despeito do discurso de profissionalização da docência, os relatos dos professores entrevistados revelaram que a trajetória do docente é em grande parte individual e pautada por iniciativas pessoais.

Este estudo partiu do entendimento de que o elemento mais importante para as universidades que pretendem se sobressair frente à competição do setor é um corpo docente capacitado e adequado ao contexto do ensino superior (NASSIF; HANASHIRO; TORRES, 2010). Nos depoimentos dos profissionais entrevistados, foi possível verificar unanimidade em relação à importância de o professor motivar e reter os estudantes na graduação. Mesmo considerando uma possível "supervalorização" da função pelos próprios profissionais, 
todos enfatizaram o valor de seus esforços e estratégias para tornarem as aulas mais interessantes e proporcionar a aprendizagem dos estudantes.

Percebe-se que, de maneira geral, a concepção de competência docente no âmbito da gestão universitária restringe-se ao conhecimento aprofundado da disciplina a ser ensinada, podendo este ser decorrente tanto do exercício profissional, quanto do exercício acadêmico ou da titulação (BOUZADA; KILIMNIK; OLIVEIRA, 2012). Confirmando outros estudos que investigaram a construção das competências docentes (ANASTASIOU; PIMENTA, 2002; BOUZADA; KILIMNIK; OLIVEIRA, 2012), os dados levantados nesta pesquisa revelaram que as universidades pouco exigem em termos pedagógicos. Esse fato não seria um problema se as instituições universitárias mantivessem ações focadas no desenvolvimento de competências fundamentais, de maneira que permitissem aos professores melhorarem seu desempenho e agregarem valor aos alunos e à própria instituição (NASSIF; HANASHIRO; TORRES, 2010). Porém, nas trajetórias analisadas neste estudo, os profissionais deram menor destaque aos fatores institucionais para o aperfeiçoamento de suas competências.

Mesmo considerando os argumentos teóricos aqui apresentados sobre competências profissionais (LE BOTERF, 1994; MOURA; BITENCOURT, 2006; FEUERSCHÜTTE; GODOI, 2011) e competências docentes (PERRENOUD, 1998; TARDIF, 2000; PERRENOUD; THURLER, 2009), acerca dos quais a formação do docente é contínua e atrelada ao contexto, é consenso de tais fundamentos que as competências precisam ser constantemente identificadas e desenvolvidas. Conforme afirmaram Nassif, Hanashiro e Torres (2010), a disposição pessoal e os esforços de autodesenvolvimento empreendidos pelos profissionais para se tornarem professores são louváveis, mas não suficientes.

Considerando a velocidade das mudanças nos conhecimentos válidos e no mercado de trabalho para o qual as universidades formam seus estudantes, a competência primordial de ensinar tornou-se um domínio em progresso. Para dar conta desse domínio, faz-se necessário ampliar o referencial do que é ensinar, confrontando as diversas representações, reconhecendo os problemas que cada uma traz, bem como identificando as próximas etapas que cada uma anuncia (PERRENOUD, 1998). Nesse sentido, este estudo buscou contribuir com uma apreciação das competências docentes por meio de três fatores constitutivos e inter-relacionados, sendo eles: individuais, colaborativos e institucionais.

Com relação a fatores individuais da prática docente, o estudo de caso apontou que os entrevistados sentem necessidade de aprimorar suas competências não apenas técnicas, mas comportamentais e relacionais. 0s três profissionais mencionaram situações bastante inusitadas que vivenciaram dentro e fora de sala de aula. No caso dos profissionais que não realizaram uma formação docente inicial, notou-se ênfase ainda maior nessas situações não previstas, definidas por eles como "conflitos". Um deles chegou a declarar que 
se sentiu "frustrado" por despender muito tempo em processos relacionais e motivacionais com os estudantes em relação ao tempo empregado na explicação dos conteúdos.

Quando questionados acerca dos fatores colaborativos no desenvolvimento de suas competências, os três entrevistados comentaram que as trocas com colegas acontecem esporadicamente, por meio de interações informais "extraclasse". A esse respeito, um deles considerou tais interações bastante importantes para a construção de competências comportamentais e relacionais que possibilitem aos docentes relacionarem-se de forma positiva com os estudantes e com a instituição. Mencionou, ainda, ter atuado em conjunto com colegas para elaboração de atividades, de acordo com solicitação da coordenação do curso. Embora se trate de um exemplo casual, o entusiasmo revelado no relato do profissional acerca do trabalho colaborativo ilustra a observação de Perrenoud (1998). 0 autor afirmou que, à medida que o corpo docente se torna comprometido em um projeto, cada um passa a ser dependente do outro e a ter expectativas legítimas em termos das competências trazidas à tarefa coletiva (PERRENOUD, 1998). Perrenoud (1998) observou, ainda, que o funcionamento de um projeto constitui um primeiro nível de regulação de competências, o qual deve ser apoiado pela instituição de ensino. Além disso, todos os professores mencionaram, em tom de reprovação, colegas que seguem com posturas pedagógicas focadas no conteúdo e na autoridade do professor. Para os entrevistados, essa falta de adequação dos professores à realidade dos estudantes é um forte motivo à evasão estudantil na graduação.

Quando investigado se os fatores institucionais influenciaram na construção de suas competências, nenhum dos entrevistados afirmou se as ações ou políticas da Universidade foram influentes. De modo geral, as falas denotaram a falta de acompanhamento da Instituição acerca de seu desempenho didático-pedagógico.

Em conjunto, os dados levantados demonstraram que embora exista um discurso de profissionalização da docência e da própria gestão universitária, os professores entrevistados atribuem à prática em sala de aula o diferencial na formação de suas competências. Um fato interessante é que o professor que teve formação pedagógica demonstrou menor relevância às dificuldades decorrentes de conflitos e processos relacionais com os estudantes. Uma possível explicação reside no preparo que as formações em nível de licenciatura, mestrado e doutorado fornecem ao profissional interessado em seguir a carreira docente.

Outra questão inferida a partir das entrevistas é que o propósito do docente em lecionar pode ser um fator de grande influência em seu desempenho e no desenvolvimento de suas competências. No caso dos professores pesquisados, um dos entrevistados caracterizou a docência como um propósito secundário em relação a seus interesses profissionais e demonstrou maior resistência em superar os desafios e dificuldades pedagógicos e relacionais junto aos estudantes. Nesse sentido, cabe a recomendação de que as instituições de ensino investiguem e levem em conta qual o propósito do docente em relação a lecionar. 
Por fim, deve-se observar que este estudo possui limitações, especialmente no que diz respeito à quantidade de profissionais entrevistados. Recomenda-se a continuidade do estudo, de maneira a englobar um perfil maior de professores, bem como incluir na análise a perspectiva da Instituição acerca da formação das competências docentes. Apesar disso, o esforço empreendido no estudo procurou contribuir com Perrenoud (1998) e outros autores, no sentido de fornecer informações sobre as práticas de ensino, visando oferecer uma imagem realista dos problemas que os professores precisam resolver todos os dias, dos dilemas que enfrentam, das decisões que tomam e dos gestos profissionais que realizam.

Embora se atribua ao professor papel decisivo em relação ao ensino, é preciso acrescentar que as instituições de educação superior, como organizações complexas, têm por objetivo principal a formação de pessoas e de profissionais que atuarão na sociedade. Nesse sentido, a responsabilidade pelo trabalho docente não deve recair apenas sobre os docentes. Há necessidade de propiciar condições objetivas de trabalho aos professores, para que possam se desenvolver como pessoas e como profissionais competentes.

\section{REFERÊNCIAS}

ANASTASIOU, L. G. C.; PIMENTA, S. G. Docência no ensino superior. São Paulo: Cortez, 2002. v. 1.

BONFM, R. Competência profissional: uma revisão bibliográfica. Revista Organização Sistêmica, Curitiba, v. 1, n. 1, p. 46-63, 2012. Disponivel em: https://www.uninter.com/revistaorganizacaosistemica/index. php/organizacaoSistemica/article/view/62. Acesso em: 10 jul. 2018.

BOUCHIKHH, H.; KIMBERLY, J. R. 'It's difficult to innovate': The death of the tenured professor and the birth of the knowledge entrepreneur. Human Relations, v. 54, n. 1, p. 77-84, 2001. Disponivel em: https:// www.researchgate.net/publication/228197426_It's_Difficult_to_Innovate'_The_Death_of_the_Tenured_Professor_and_the_Birth_of_the_Knowledge_Entrepreneur. Acesso em: 20 jun. 2018.

BOUZADA, V. C. P. C.; KILIMNIK, Z. M.; OLIVEIRA, L. C. V. de. Professor iniciante: desafios e competências da carreira docente de nível superior e inserção no mercado de trabalho. Revista de Carreiras e Pessoas (ReCaPe), v. 2, n. 1, p. 1-18, 2012. Disponível em: https://revistas.pucsp.br/index.php/ReCaPe/ article/viewFile/9336/7006. Acesso em: 26 jun. 2018.

BRAUN, V.; CLARKE, V. Using thematic analysis in psychology. Qualitative research in psychology, v. 3 , n. 2, p. 77-101, 2006. Disponivel em: https://www.tandfonline.com/doi/abs/10.1191/1478088706qp063oa. Acesso em: 12 jul. 2018.

EGRY, E. Y.; MARQUES, C. M. S.; FONSECA, R. M. G. S. A avaliação de competências na perspectiva crítico-emancipatória. Ciência, Cuidado e Saúde, v. 5, n. 2, p. 236-242, 2006. Disponível em: http://www. periodicos.uem.br/ojs/index.php/CiencCuidSaude/article/view/5087. Acesso em: 20 jul. 2018. 
ESTEVES, M. Construção e desenvolvimento das competências profissionais dos professores. Sisifo. Revista de Ciências da Educação, v. 8, p. 37-48, 2009. Disponível em: http://centrorecursos.movimentoescolamoderna.pt/dt/3_2_formacao_professores/32_21_constru_desenv_competencias_prof_ mesteves.pdf. Acesso em: 22 jun. 2018.

FERNANDES, B. Gestão Estratégica de Pessoas: com foco em competências. São Paulo: Elsevier Brasil, 2013.

FEUERSCHÜTTE, S. G.; GODOI, C. K. Metodologia de identificação de competências gerenciais: uma proposta com base na história de vida de gerentes seniores. Revista Alcance, v. 18, n. 3, p. 321-340, jul./ set. 2011. Disponivel em: http://www.spell.org.br/documentos/ver/2753/metodologia-de-identificacao-de-competencias-gerenciais--uma-proposta-com-base-na-historia-de-vida-de-gerentes-seniores. Acesso em: 5 jul. 2018.

FLEURY, M. T. L.; FLEURY, A. C. C. Alinhando estratégia e competências. Revista de Administração de Empresas, v. 44, n. 1, p. 44-57, 2004. Disponivel em: https://rae.fgv.br/rae/vol44-num1-2004-0/ alinhando-estrategia-competencias. Acesso em: 30 jun. 2018.

GUMPORT, P. J.; SPORN, B. Institutional adaptation: Demands for management reform and university administration. Higher education: Handbook of theory and research, Springer, Dordrecht, p. 103-145, 1999. Disponivel em: http://citeseerx.ist.psu.edu/viewdoc/summary?doi=10.1.1.183.3708. Acesso em: 24 jun. 2018.

HAWAWINI, G. The future of business schools. Journal of Management Development, v. 24, n. 9, p. 770782, 2005. Disponivel em: https://www.emeraldinsight.com/doi/abs/10.1108/02621710510621286?fullSc=1\& journalCode=jmdAcesso em: 20 jul. 2018.

INSTITUTO NACIONAL DE ESTUDOS E PESQUISAS EDUCACIONAIS ANISIO TEIXEIRA. Censo Escolar da Educação Superior 2015. Brasília, DF: Ministério da Educação/ INEP, 2015. Disponível em: http://portalinep.gov. br/censo-da-educacao-superior. Acesso em: 24 jun. 2018.

LE BOTERF, G. De la compétence: essai sur um attracteur étrange. Paris: Éditions d’ Organisation, 1994.

MEYER JUNIOR, V.; MURPHY, P. (org.). Dinossauros, gazelas \& tigres: novas abordagens da administração universitária. Um diálogo entre Brasil e Estados Unidos. 2. ed. Florianópolis: Insular, 2003.

MINTZBERG, H. MBA? Não, obrigado: Uma visão crítica sobre a gestão e o desenvolvimento de gerentes. Porto Alegre: Bookman, 2006.

MOURA, M. C. C. de; BITENCOURT, C. C. A articulação entre estratégia e o desenvolvimento de competências gerenciais. Revista de Administração de Empresas, v. 5, n. 1, 2006. Disponivel em: http://www. scielo.br/pdf/raeel/v5n1/29560.pdf. Acesso em: 30 jun. 2018. 
NASSIF, V. M. J.; HANASHIRO, D. M. M.; TORRES, R. R. Fatores que influenciam na percepção das competências para o exercício da docência. Revista Brasileira de Educação, v. 15, n. 44, p. 364-379, 2010. Disponível em: http://www.scielo.br/scielo.php?pid=S1413-24782010000200012\&script=sci_abstract\&tlng=pt. Acesso em 08 jul. 2018.

PERRENOUD, P. Dez novas competências para ensinar. Porto Alegre: Artes Médicas, 2000.

PERRENOUD, P. Formação contínua e obrigatoriedade de competências na profissão de professor. Série Ideias, v. 30, p. 205-251, 1998. Disponível em: https://www.unige.ch/fapse/SSE/teachers/perrenoud/php_main/php_1998/1998_48.html. Acesso em: 20 jul. 2018.

PERRENOUD, P.; THURLER, M. G. As competências para ensinar no século XXI: a formação dos professores e o desafio da avaliação. Porto Alegre: Artmed Editora, 2009.

RICARDO, E. C. A discussion about learning competences: problems and alternatives. Cadernos de pesquisa, v. 40, n. 140, p. 605-628, 2010. Disponivel em: http://www.scielo.br/pdf/cp/v40n140/a1540140. pdf. Acesso em 25 jul. 2018.

RICHARDSON, R. J. et al. Pesquisa social: métodos e técnicas. 3. ed. São Paulo: Atlas, 2008.

RUAS, R.; ANTONELLO, C. S.; BOFF, L. H. Os novos horizontes de gestão: aprendizagem organizacional e competências. Porto Alegre: Bookman Editora, 2005.

SCHUGURENSKY, D. The political economy of higher education in the time of global markets: Whither the social responsibility of the university. Research gate, 2006. Disponivel em: https://www.researchgate. net/publication/310482135_The_political_economy_of_higher_education_in_the_time_of_global_ markets_Whither_the_social_responsibility_of_the_university. Acesso em: 29 jun. 2018.

STASZ, C. Do employers need the skills they want? Evidence from technical work. Journal of Education and Work, v. 10, n. 3, p. 205-223, 1997. Disponivel em: https://www.tandfonline.com/doi/ abs/10.1080/1363908970100301. Acesso em 30 jun. 2018.

TARDIF, M. Saberes profissionais dos professores e conhecimentos universitários. Revista Brasileira de Educação, v. 13, n. 5, p. 5-24, 2000. Disponivel em: http://anped.tempsite.ws/novo_portal/rbe/rbedigital/RBDE13/RBDE13_05_MAURICE_TARDIF.pdf. Acesso em: 10 jul. 2018.

TIMES HIGHER EDUCATION. World University Ranking 2015-2016. 13 jun. 2016. Disponivel em: https://www. timeshighereducation.com/search/country/Brazil/type/ranking_institution. Acesso em: 10 jul. 2018.

YIN, R. Estudo de caso: Planejamento e métodos. Porto Alegre: Bookman, 2004.

Endereços para correspondência: Rua Des. José Carlos Ribeiro Ribas, 1.409, 82130-300, Curitiba, Paraná, Brasil; alboni@alboni.com 